\title{
NÍVEL DE CONTROLE DE Diloboderus abderus EM AVEIA PRETA, LINHO, MILHO E GIRASSOL
}

\author{
CONTROL LEVEL OF Diloboderus abderus IN BLACK OATS, FLAX, CORN AND SUNFLOWER
}

\author{
Mauro Tadeu Braga da Silva ${ }^{1}$ Ervandil Corrêa Costa ${ }^{2}$
}

\section{RESUMO}

$O$ estudo aqui relatado foi conduzido nas safras agrícolas de 1991 e 1992, em Cruz Alta, no Rio Grande do Sul. O objetivo foi avaliar o efeito de diferentes níveis de infestação de Diloboderus abderus Sturm, 1826 (Coleoptera: Melolonthidae) em aveia preta (Avena strigosa L.), em linho (Linum usitatissimum L.), em milho (Zea mays L.) e em girassol (Helianthus annuus L.), no sistema de plantio direto. $O$ aumento do número de larvas $/ \mathrm{m}^{2}$ propiciou a ocorrência de danos e, em conseqüência, a diminuição da população de plantas, da massa seca da parte aérea e da produtividade. Os níveis de controle obtidos foram variáveis dependendo da cultura. Com base nos danos produzidos pelo inseto, sugerem-se os níveis de controle de 12 larvas $/ \mathrm{m}^{2}$ em linho, de 10 larvas $/ \mathrm{m}^{2}$ em aveia preta, de 0,5 larva/ $\mathrm{m}^{2}$ em milho e de 0,4 larva/ $\mathrm{m}^{2}$ em girassol, como indicador para tratamento de sementes destas culturas com inseticidas.

Palavras-chave: Insecta, coró, controle, plantas danificadas, plantio direto.

\section{SUMMARY}

The study was carried out in the 1991 and 1992 growing seasons, in Cruz Alta, Rio Grande do Sul State. The objective was to evaluate the infestation levels of Diloboderus abderus Sturm, 1826 (Coleoptera: Melolonthidae) on black oats (Avena strigosa L.), flax (Linum usitatissimum L.), corn (Zea mays L.) and sunflower (Helianthus annuus L.) under no-tillage. Increasing number of larvae/ $m^{2}$ decreased plant population, plant biomass and yield. Control levels were different among the four crops species. Results of the insect damage suggested the control level of 12 larvae $/ \mathrm{m}^{2}$ in flax, 10 larvae $/ \mathrm{m}^{2}$ in black oats, 0.5 larva/ $\mathrm{m}^{2}$ in corn and 0.4 larva/ $\mathrm{m}^{2}$ in sunflower as indicator for these crops seed treatment with insecticides.

Key words: Insecta, white grubs, control, damaged plants, notillage.

\section{INTRODUÇÃO}

No final da década de 80 , um complexo de larvas da família Melolonthidae, comumente chamadas de corós atingiram a condição de praga, causando danos às culturas de inverno e de início de primavera, em algumas regiões do Rio Grande do Sul. Dentro desse complexo, destaca-se a espécie Diloboderus abderus Sturm, 1826 (Coleoptera), que é conhecida pelos agricultores como "coró-daspastagens".

D. abderus é uma espécie univoltina, desenvolvendo-se no solo, entre 10 e $19 \mathrm{~cm}$ de profundidade. Os ovos ocorrem de janeiro a abril, as larvas de fevereiro a novembro, as pupas de outubro a dezembro e os adultos de novembro a abril (SILVA \& LOECK, 1996).

$\mathrm{O}$ inseto é polífago alimentando-se de plantas de diversas famílias. As larvas têm hábitos subterrâneos e ingerem, principalmente, raízes de numerosas espécies de plantas usadas em cultivos de lavouras, de hortaliças e de forrageiras, além de pastagens naturais ou artificiais e gramados (COSTA, 1958; BAUCKE, 1965; SILVA et al., 1968; GALARZA, 1972; GUERRA et al., 1976; MOREY \& ALZUGARAY, 1982; ALVARADO, 1983; GASSEN, 1989).

ALVARADO $(1980 ; 1989)$ relata que o efeito prejudicial do inseto é evidente na fase inicial de desenvolvimento das plantas de milho, quando as densidades são superiores a 4 larvas $/ \mathrm{m}^{2}$. SILVA (1997), baseando-se nos danos produzidos pelo

\footnotetext{
${ }^{1}$ Engenheiro Agrônomo, Mestre, Pesquisador da FUNDACEP FECOTRIGO, CP 10, 98100-970, Cruz Alta, RS. E-mail: fundacep@comnet.com.br. Autor para correspondência.

${ }^{2}$ Engenheiro Agrônomo, Doutor, Pesquisador do CNPq, Professor Titular, Departamento de Defesa Fitossanitária, Centro de Ciências Rurais, Universidade Federal de Santa Maria, 97105-900, Santa Maria, RS. E-mail: eccosta@ccr.ufsm.br.

Recebido para publicação em 12.12.00. Aprovado em 25.04.01
} 
inseto, sugere o nível de controle de 5 larvas $/ \mathrm{m}^{2}$ como indicador para o tratamento de sementes de trigo com inseticidas. GASSEN (1999) menciona que 4 larvas $/ \mathrm{m}^{2}$ pode causar a morte de 24 a 32 plantas de aveia ou de trigo, num período de dois meses, reduzindo em $10 \%$ a população de plantas.

O nível de dano econômico (NDE) e o nível de controle (NC) são duas definições importantes e contrastam com aqueles tipos de controle de caráter profilático, que preconizam a aplicação de inseticidas seguindo o calendário, com o fim de erradicar os insetos da área infestada. O primeiro caso é a menor densidade populacional de um inseto que causa dano a uma cultura, devendo-se aplicar medidas de controle para manter a população abaixo do NDE (MACCARINI, 1987). O segundo caso é a densidade populacional de um inseto que. no eixo Y, corresponde ao dano causado pela praga, considerado igual ao custo de controle (NAKANO et al., 1981). Portanto, quando uma população de insetos se eleva, passando pelo NC, pode produzir um dano que compense o controle da área e/ou da cultura.

Devido à ocorrência expressiva de $\boldsymbol{D}$. abderus em determinados anos e a escassez de pesquisas que quantifiquem os prejuízos causados pelas larvas às plantas, avaliou-se o nível de controle nas culturas de aveia preta, linho, milho e girassol semeadas no sistema de plantio direto, em duas safras agrícolas.

\section{MATERIAL E MÉTODOS}

Oito experimentos foram conduzidos na Fundacep Fecotrigo, em Cruz Alta - RS, num Latossolo Vermelho Escuro distrófico, textura argilosa, com 55 a $60 \%$ de argila e 3,0 a $3,2 \%$ de matéria orgânica, durante as safras 1991 e 1992, em áreas experimentais com 2 e 3 anos de plantio direto, respectivamente.

A aveia preta (cultivar comum) e linho (cultivar Taperajú) foram semeadas com espaçamento de $0,20 \mathrm{~m}$ entre fileiras e 450 e 1000 sementes $/ \mathrm{m}^{2}$, respectivamente. O milho (variedade CEP 304) foi semeado com espaçamento de $1,00 \mathrm{~m}$ entre fileiras e 6 sementes $/ \mathrm{m}$. O girassol (cultivar GR 10) foi semeado com espaçamento de $0,50 \mathrm{~m}$ entre fileiras e 4 sementes $/ \mathrm{m}$. O delineamento experimental utilizado foi de blocos ao acaso com cinco repetições e cinco tratamentos, representados pelos níveis de infestação de larvas de $\boldsymbol{D}$. abderus em parcelas com área de $1,0 \mathrm{~m}^{2}$. As semeaduras ocorreram em 01/07/1991 e 14/06/1992 para aveia preta, 24/06/1991 e 15/06/1992 para linho e 20/08/1991 e 28/08/1992 para milho e girassol. Antes da semeadura das culturas, larvas de $3^{\mathrm{o}}$ ínstar foram colocadas nas parcelas, a uma profundidade de 10 a $15 \mathrm{~cm}$, nos seguintes níveis populacionais: 0 , $5,10,20$ e $40 / \mathrm{m}^{2}$ para aveia preta e linho e $0,2,4,8$ e $16 / \mathrm{m}^{2}$ para milho e girassol. As infestações foram realizadas durante todo o ciclo das culturas. Para evitar a disseminação das larvas entre as parcelas experimentais, foram colocadas placas galvanizadas quadradas (1,5m de lado e 0,20 de altura), enterradas a $0,05 \mathrm{~m}$ no solo, individualizando cada parcela, sendo mantidas até a emergência dos adultos.

A adubação de base e de cobertura, o controle de plantas daninhas e de tratamentos fitossanitários foram executados de acordo com as recomendações técnicas para cada cultura.

Foram avaliados a população inicial e final de plantas, a massa seca da parte aérea e a produtividade de grãos por parcela. Para avaliação da massa seca, as plantas foram cortadas rente ao solo, logo após a colheita, e colocadas em estufa a $70^{\circ} \mathrm{C}$, durante 48 horas. Com relação à produtividade, corrigiu-se a umidade de grãos para $13 \%$ após a pesagem.

Os resultados foram representados pela equação linear e pelo coeficiente de determinação $\left(\mathrm{r}^{2}\right)$, enquanto a relação entre a produtividade obtida e o nível de infestação de larvas foi expressa pelos pontos de nível de controle (NC). Esses pontos foram calculados através da seguinte fórmula proposta por SILVA (1997):

\section{$\mathrm{Z}=\mathrm{Qs} \times \mathrm{Ci} / \mathrm{Cs}$}

$\mathrm{Z}=$ custo em reais da aplicação (gramas $/ \mathrm{m}^{2}$ )

Qs = quantidade de semente (1 grama)

$\mathrm{Ci}=$ valor em reais do inseticida via sementes de aveia preta $\left(0,0037 / \mathrm{m}^{2}\right)$

linho $\left(0,0032 / \mathrm{m}^{2}\right)$ milho $\left(0,0020 / \mathrm{m}^{2}\right)$ girassol $\left(0,0013 / \mathrm{m}^{2}\right)$

$\mathrm{Cs}=$ valor em reais da semente de aveia preta $(0,00019 /$ grama $)$

valor em reais da semente de linho $(0,0003 /$ grama $)$ valor em reais da semente de milho (0,0002/grama) valor em reais da semente de girassol $(0,0003$ /grama)

onde se calculou

$\mathrm{NC}(\mathrm{X})=\mathrm{Z} / \mathrm{b}$

$\mathrm{NC}(\mathrm{X})=$ número de larvas $/ \mathrm{m}^{2}$

$\mathrm{b}=$ coeficiente " $\mathrm{b}$ " da equação

$\mathrm{NC}(\mathrm{Y})=\mathrm{a}-\mathrm{Z}$

$\mathrm{NC}(\mathrm{Y})=$ produtividade com o custo da aplicação

$\mathrm{a}=$ coeficiente " $\mathrm{a}$ " da equação ou produtividade sem o custo da aplicação

Ciência Rural, v. 32, n. 1, 2002. 
Também foram obtidas correlações simples entre as variáveis, nível de infestação e produtividade com a população inicial, a população final e a massa seca de plantas.

\section{RESULTADOS E DISCUSSÃO}

As análises de regressão entre produtividade média das culturas por $\mathrm{m}^{2}$ e os níveis de infestação proposto mostraram que o melhor ajuste ocorreu com a regressão quadrática, porém usou-se o ajuste linear devido à pequena contribuição do efeito quadrático e à dificuldade para o cálculo dos níveis de controle (Figuras 1A, $1 \mathrm{~B}, 2 \mathrm{~A}, 2 \mathrm{~B}$ e $2 \mathrm{C}$ ).

Os valores dos coeficientes de determinação anuais obtidos para aveia preta foram de 0,98 (1991) e 0,99 (1992) e significativos (Figuras 1A e 1B). Para o linho 0,91, para o milho 0,84 e para o girassol 0,90 e significativos (Figuras 2A, 2B e 2C).

Para a aveia preta, não foi realizada análise de regressão conjunta dos dois anos, devido à interação anos $\mathrm{x}$ tratamentos ter sido significativa. Isto ocorreu, possivelmente, devido ao maior vigor vegetativo e reprodutivo apresentado pelas plantas de aveia preta em 1992 (chuvas acima da normal, especialmente em setembro e outubro) em relação à safra 1991 (chuvas abaixo da normal, entre julho e novembro). Por outro lado, para o linho, o milho e o girassol foram realizadas análises de regressão conjuntas dos dois anos, porque as interações anos $\mathrm{x}$ tratamentos não foram significativas.

Os valores dos coeficientes de determinação e os coeficientes "b" negativos das equações (Figuras 1A, 1B, 2A, 2B e 2C) demonstraram alta relação entre a produtividade de grãos das culturas e o nível de infestação do inseto, indicando que a produtividade diminui à medida que ocorre um aumento do número de larvas $/ \mathrm{m}^{2}$. Esses resultados evidenciam, ainda, que a contagem de larvas pode ser usada para amostragem do nível populacional do inseto, porque está correlacionada à produtividade das plantas de aveia preta, de linho, de milho e de girassol.

Os coeficientes de correlação linear negativos entre as variáveis nível de infestação do inseto e a população inicial de plantas, a massa seca de plantas e a população final de plantas, significam que, com o aumento do número de larvas $/ \mathrm{m}^{2}$, a população de plantas e a quantidade de massa seca da parte aérea são afetadas (Tabela 1). Os coeficientes de correlação linear positivos entre as variáveis produtividade da plantas e a população inicial de plantas, a massa seca de plantas e a população final de plantas indicam que a redução do número de plantas e da quantidade de massa seca provoca perdas na produtividade (Tabela 1). No linho, tanto em 1991 quanto em 1992, a causa de as correlações entre nível de infestação e população inicial e massa seca e entre produtividade e massa seca não terem sido significativas, pode ser atribuída à densidade de semeadura (1000 sementes $/ \mathrm{m}^{2}$ ) que esta cultura exige, resultando numa elevada população de plantas por área (Tabela 1). Apenas em 1992, a causa de as correlações entre produtividade e massa seca de

Figura 1 - Regressão linear entre produtividade de plantas de aveia preta, em 1991 (A) e 1992 (B) e níveis de larvas de de Diloboderus abderus e nível de controle (NC), durante duas safras agrícolas. Cruz Alta, RS. 2000.

Ciência Rural, v. 32, n. 1, 2002. 


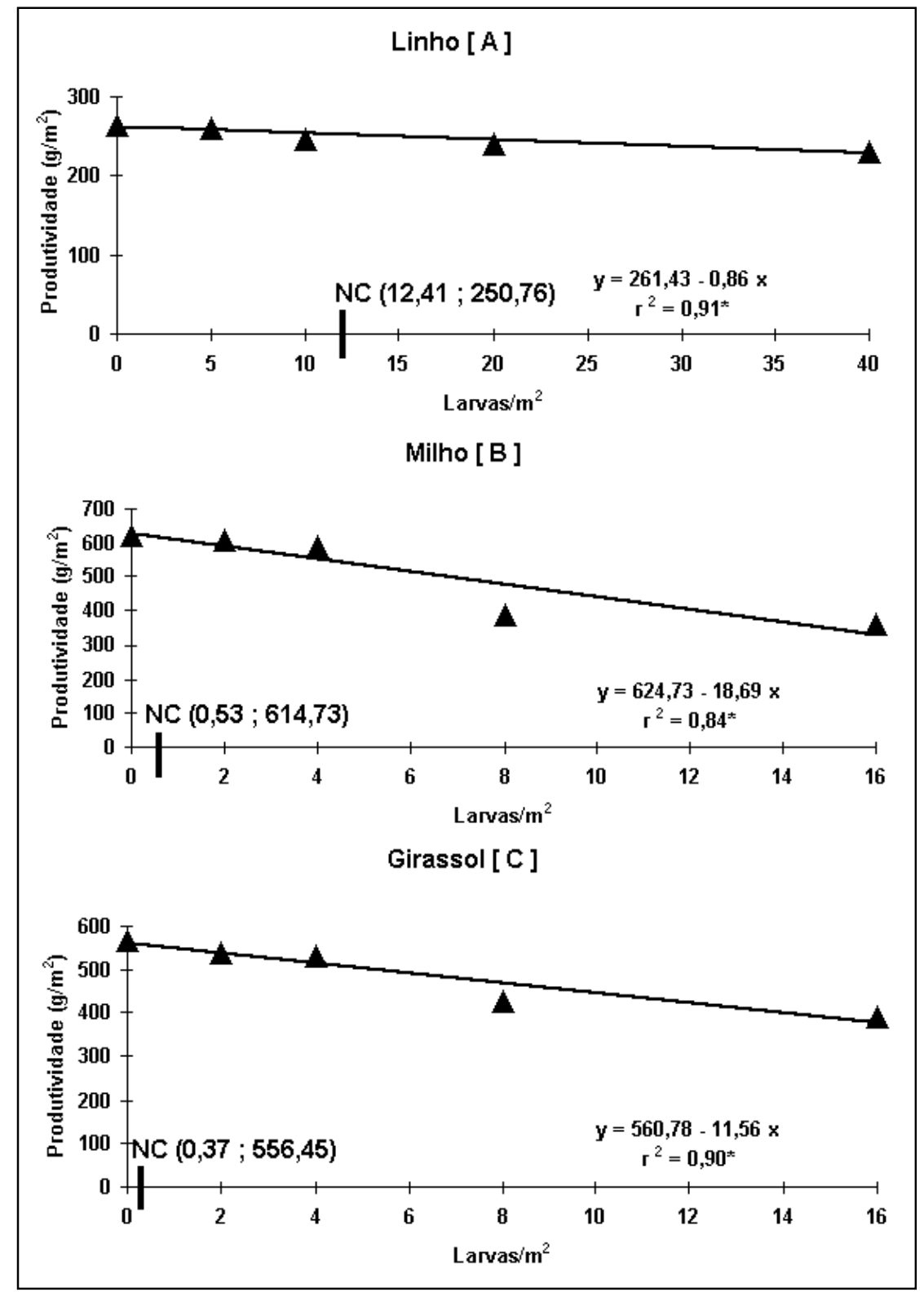

Figura 2 - Regressão linear entre produtividade de plantas de linho (A), de milho (B) e de girassol (C) e níveis de larvas de de Diloboderus abderus e nível de controle (NC), durante duas safras agrícolas. Cruz Alta, RS. 2000.

plantas de aveia preta e entre população inicial de plantas de milho e de girassol com nível de infestação e produtividade não terem sido significativas, pode ser devida às condições ótimas de chuva verificada durante todo o ciclo das culturas, diminuindo o estresse das plantas, que conseguiram recuperação.

Considerando o custo das sementes e do inseticida para aplicação via sementes, além dos cálculos feitos para o tamanho da área útil de cada parcela $\left(1 \mathrm{~m}^{2}\right)$, determinou-se o custo da aplicação
(Z) no eixo $\mathrm{Y}$ de 19,47 gramas de aveia preta, de 10,67 gramas de linho, de 10,0 gramas de milho e de 4,33 gramas de girassol, que são iguais ao dano causado pelo inseto. Esse valor dividido pelo coeficiente " $b$ " das equações resultou em 12,70 (1991) e em 6,64 (1992) larvas $/ \mathrm{m}^{2}$ para aveia preta (Figuras 1A e 1B), em 12,41 larvas $/ \mathrm{m}^{2}$ para o linho (Figura 2A), em 0,53 larva/ $\mathrm{m}^{2}$ para o milho (Figura 2B), e em 0,37 larva $/ \mathrm{m}^{2}$ para $\mathrm{O}$ girassol (Figura 2C), sendo estes os níveis de controle NC (X) do inseto. Essas densidades $/ \mathrm{m}^{2}$ são os números ajustados para larvas considerando os mesmos níveis equivalentes ao custo da aplicação NC (Y), que foram de 184,88 gramas, em 1991, e 326,56 gramas, em 1992, de aveia preta, de 250,76 gramas de linho, de 614,73 gramas de milho e de 556,45 de girassol.

Com base nos resultados dos danos produzidos pelas larvas de $\boldsymbol{D}$. abderus às plantas, sugere-se o nível de controle de 10 larvas $/ \mathrm{m}^{2}$ para aveia preta, de 12 larvas $/ \mathrm{m}^{2}$ para linho, de $0,5 \mathrm{larva} / \mathrm{m}^{2}$ para milho e de $0,4 \mathrm{larva} / \mathrm{m}^{2}$ para girassol, como indicador para uso de inseticidas via tratamento de sementes. Este valor foi $o$ número de larvas aproximado e ajustado para o nível equivalente ao custo da aplicação. Os resultados revelam também reação diferenciada entre as espécies vegetais ao ataque do inseto. A aveia preta e o linho são mais tolerantes à ação das larvas em relação ao milho e ao girassol. O trigo, considerando os resultados obtidos por SILVA (1997), com nível de controle de 5 larvas $/ \mathrm{m}^{2}$, fica colocado em posição intermediária em relação às culturas avaliadas neste estudo.

Cabe, no entanto, destacar que o nível de controle pode variar de uma área para outra dentro 
Tabela 1 - Coeficientes de correlação linear (r) entre níveis de larvas de Diloboderus abderus e produtividade com a população inicial, a massa seca e a população final de plantas de aveia preta, de linho, de milho e de girassol. Cruz Alta, RS. 2000.

\begin{tabular}{lcc}
\hline \multirow{2}{*}{ Variáveis } & \multicolumn{2}{c}{$\begin{array}{c}\text { Coeficientes e probabilidades de correlações }{ }^{1} \\
\text { Safras agrícolas }\end{array}$} \\
\cline { 2 - 3 } & 1991 & 1992 \\
\hline
\end{tabular}

Aveia preta

Nível x população inicial

Nível x massa seca

Produtividade $\mathrm{x}$ população inicial

Produtividade $\mathrm{x}$ massa seca

$$
\begin{array}{cc}
r=-0,67(0,0002 *) & r=-0,71(0,0001 *) \\
r=-0,50(0,0118 *) & r=-0,40(0,0501 *) \\
r=0,41(0,0441 *) & r=0,56(0,0037 *) \\
r=0,50(0,0101 *) & r=0,28(0,1704 \mathrm{~ns})
\end{array}
$$

Nível x população inicial

Nível x massa seca

Produtividade $x$ população inicial

Produtividade $\mathrm{x}$ massa seca

$$
\begin{aligned}
& \text { Linho } \\
& r=-0,17(0,4169 \mathrm{~ns}) \quad \mathrm{r}=-0,16(0,4502 \mathrm{~ns}) \\
& r=-0,32(0,1213 \mathrm{~ns}) \quad \mathrm{r}=-0,06(0,7562 \mathrm{~ns}) \\
& \mathrm{r}=0,14(0,4948 \mathrm{~ns}) \quad \mathrm{r}=0,05(0,8076 \mathrm{~ns}) \\
& \mathrm{r}=0,47(0,0169 *) \quad \mathrm{r}=0,53(0,0066 *) \\
& \text { Milho } \\
& r=-0,67(0,0003 *) \quad r=-0,35(0,0813 \mathrm{~ns}) \\
& r=-0,88(0,0001 *) \quad r=-0,68(0,0002 *) \\
& \mathrm{r}=0,75(0,0001 *) \quad \mathrm{r}=0,18(0,3889 \mathrm{~ns}) \\
& \mathrm{r}=0,95(0,0001 *) \quad \mathrm{r}=0,82(0,0001 *)
\end{aligned}
$$

Nível x população inicial

Nível x população final

Produtividade x população inicial

Produtividade $\mathrm{x}$ população final

$$
\begin{array}{lcc}
\text { Nível x população inicial } & r=-0,49(0,0124 *) & r=-0,07(0,7413 \mathrm{~ns}) \\
\text { Nível x população final } & r=-0,50(0,0100 *) & r=-0,57(0,0028 *) \\
\text { Produtividade x população inicial } & r=0,73(0,0001 *) & r=0,05(0,8041 \mathrm{~ns}) \\
\text { Produtividade x população final } & r=0,50(0,0106 *) & r=0,67(0,0003 *)
\end{array}
$$

${ }^{1}$ Probabilidades estimadas por Pearson: * = nível de significância de 5\% de probabilidade de erro e ns = não significativo.

duma mesma região devido ao clima, solo, fertilidade, época de semeadura, cultivares ou variedades ou híbridos, inimigos naturais, custos de insumos e sucessão ou rotação de culturas. Portanto, tais fatores, que não foram uniformizados neste estudo, podem influenciar o ajustamento do nível de controle ideal. Assim, os níveis de controle obtidos devem ser enquadrados apenas como um parâmetro relativo na tomada de decisão para o controle do inseto em questão.

\section{CONCLUSÃO}

Os níveis de controle para larvas rizófagas de $\boldsymbol{D}$. abderus em linho, aveia preta, milho e girassol foram de $12 ; 10 ; 0,5$ e 0,4 larva $/ \mathrm{m}^{2}$, respectivamente.

\section{AGRADECIMENTOS}

Os autores agradecem ao professor Lindolfo Storck, do Departamento de Fitotecnia do CCR/UFSM, e ao pesquisador
Ricardo Guilherme Matzenbacher, da Fundacep Fecotrigo, pelas sugestões na elaboração das análises estatísticas e pelas sugestões em versões preliminares do manuscrito, respectivamente.

\section{REFERÊNCIAS BIBLIOGRÁFICAS}

ALVARADO, L. Plagas: insectos del suelo. In: DAMILANO, A.L.; BRUGNONI, L. Coleccion principales cultivos de la Argentina; el cultivo del maíz. Buenos Aires : INTA, 1980. p.88-94.

ALVARADO, L. Dãnos de insectos del suelo en semillas del plantas cultivadas. Pergamino: INTA/EERA, 1983. 7p. (Informe Tecnico, 180).

ALVARADO, L. Amostragem de insetos de solo. In: REUNIÃO SUL-BRASILEIRA DE INSETOS DE SOLO, 2, 1989. Londrina, PR. Ata ... Londrina: EMBRAPA-CNPSo, 1989. p.34-37.

BAUCKE, O. Notas taxonômicas e biológicas sobre Diloboderus abderus (Sturm, 1826) Coleoptera-Scarabaeidae-Dynastinae. Revista da Faculdade de Agronomia e Veterinária, Porto Alegre, v.7, p.113-135, 1965.

COSTA, R.G. Alguns insetos e outros pequenos animais que danificam plantas cultivadas no Rio Grande do Sul. Porto Alegre: UFRGS, 1958. 296p.

GALARZA, J. Control de insectos del suelo Que prejudican al maíz. Pergamino: INTA/EERA, 1972. 11p. (Informe Tecnico, 115).

GASSEN, D.N. Insetos subterrâneos prejudiciais às culturas no sul do Brasil. Passo Fundo : EMBRAPA-CNPT, 1989. 49p. (Documentos, 13).

GASSEN, D.N. Manejo de Diloboderus Abderus em lavouras e pastagens no sul do Brasil. In: REUNIÃO LATINO AMERICANA DE SCARABAEOIDOLOGIA, 4, 1999, Viçosa, MG. Memórias ... Viçosa : EMBRAPA/UFV, 1999. p.113-122.

GUERRA, M.S.; LOECK, A.E.; RUDIGER, W.H. Levantamento das pragas de solo da região tritícola do Rio Grande do Sul. Divulgação Agronômica, São Paulo, n.40, p.1-5, 1976.

MACCARINI, L.D.G. Lucha integrada contra las plagas. Acta Toxicológica, Pelotas, v.8 e 9, p.1-8, 1987.

MOREY, C.S.; ALZUGARAY, R. Biologia y comportamiento de Diloboderus abderus (Sturm, 1826) (ColeopteraScarabaeidae). Montevideo: Ministerio de Agricultura y 
Pesca/Dirección de Sanidad Vegetal, 1982. 44p. (Boletín Tecnico, 5).

NAKANO, O.; SILVEIRA NETO, S.; ZUCCHI, R.A Entomologia econômica. São Paulo : Livroceres, 1981. 314p.

SILVA, A.G.d'A.; GONÇALVES, C.R.; GALVÃO, O.M., $\boldsymbol{e} \boldsymbol{t} \boldsymbol{a l}$. Quarto catálogo dos insetos que vivem nas plantas cultivadas do Brasil; seus parasitos e predadores. Rio de Janeiro : Ministério da Agricultura, 1968. V.1, pt.2, 622p.
SILVA, M.T.B. Níveis de controle de Diloboderus abderus (Sturm) em trigo no plantio direto. Anais da Sociedade Entomológica do Brasil, Londrina, v.26, n.3, p.435-440, 1997.

SILVA, M.T.B. da.; LOECK, A.E. Ciclo evolutivo e comportamento de Diloboderus abderus Sturm (Coleoptera: Melolonthidae) em condições de plantio direto. Anais da Sociedade Entomológica do Brasil, Londrina, v.25, n.2, p.329-337, 1996. 